\title{
Improving the design of long-term monitoring experiments in forests: a new method for the assessment of local soil variability by combining infrared spectroscopy and dendrometric data
}

\author{
Emila Akroume $^{1,2,3} \cdot$ Bernd Zeller $^{1} \cdot$ Marc Buée $^{2}$ Philippe Santenoise ${ }^{1}$. \\ Laurent Saint-André ${ }^{1,4}$
}

Received: 21 October 2015 / Accepted: 4 July 2016 /Published online: 31 August 2016

(C) INRA and Springer-Verlag France 2016

\begin{abstract}
- Key message Near- and mid-infrared spectroscopy allows for the detection of local patterns of forest soil properties. In combination with dendrometric data, it may be used as a

\section{Handling Editor: Erwin Dreyer}

Contribution of the co-authors E.A realized the field and laboratory work, conducted the data analyses, and wrote the paper. L.S.A, M.B, and B.Z designed the experiment, realized the field work supervised the work, and coordinated the research project. PhS developed the algorithms to analyze NIR and MIR spectra.
\end{abstract}

Electronic supplementary material The online version of this article (doi:10.1007/s13595-016-0572-3) contains supplementary material, which is available to authorized users.

Emila Akroume

emila.akroume@onf.fr

Bernd Zeller

zeller@nancy.inra.fr

Marc Buée

buee@nancy.inra.fr

Philippe Santenoise

psantenoise@nancy.inra.fr

Laurent Saint-André

st-andre@ nancy.inra.fr

1 UR 1138, Biogéochimie des Ecosystèmes Forestiers (BEF), INRA, 54280 Champenoux, France

2 UMR 1136, Interactions Arbres-Microorganismes (IAM), INRA, 54280 Champenoux, France

3 AgroParisTech, Centre de Nancy, 54000 Nancy, France

4 UMR Eco\&Sols (Ecologie Fonctionnelle \& Biogéochimie des Sols \& Agroécosystèmes), CIRAD, Place Viala,

34060 Montpellier, France prospective tool for determining soil heterogeneity before setting up long-term forest monitoring experiments.

- Context Forest soils and stands generally exhibit higher spatial heterogeneity than other terrestrial ecosystems. This variability needs be taken into account before setting up long-term forest monitoring experiments to avoid multiple interactions between local heterogeneity and the factors tested in the experiment.

- Aims We hypothesized that raw near- and mid-infrared spectra can be used as an integrated proxy of a large set of soil properties. The use of this method, in combination with dendrometric data, should provide a quick and cost-effective tool for optimizing the design of experimental forest sites.

- Methods We assessed the local soil heterogeneity at 11 experimental sites in oak and beech stands, which belong to a new forest long-term ecological research (LTER) network. We used near- and mid-infrared spectroscopy in soil and litter samples. The spectra were subjected to principal components analyses (PCA) to determine the intra-site variability of the soil and litter layers.

- Results Based on mapped PCA coordinates and basic dendrometric data, it was possible to design the experiment and minimize the interactions between the treatment layout and the tested variables. The method was validated with chemical analyses of the soil. No interaction was detected at the set-up of the experiment between the treatment layout and chemical soil properties $(\mathrm{C}, \mathrm{N}, \mathrm{C} / \mathrm{N}$ ratio, $\mathrm{pH}, \mathrm{CEC}, \mathrm{Al}, \mathrm{Mg}$, $\mathrm{P}_{2} \mathrm{O}_{5}, \mathrm{Fe}, \mathrm{Mn}, \mathrm{Na}$, and $\mathrm{K}$ ).

- Conclusion Near-infrared (NIR) and mid-infrared (MIR) spectroscopy is a useful tool for characterizing the overall heterogeneity of soil chemical properties. It can be used without any preliminary calibration. In combination with dendrometric data, it provides a reliable method for optimizing LTER plots in different types of ecosystems. 
Keywords Forest long-term ecological research · Local soil variability $\cdot$ Experimental design $\cdot$ Near-mid-infrared spectroscopy

\section{Introduction}

The current environmental context for forest ecosystems is mainly characterized by relevant global changes, in terms of land uses, energetic consumption, climate, and atmospheric depositions. These changes and their integration into research programs and forest policies occurred very recently, during the second half of the last century. The need to observe and evaluate the impacts of these major changes on forest ecosystems is highlighted in both the short and long term. These preoccupations led to the establishment of several long-term ecological research (LTER) experimental networks around the world, especially in the forest ecosystems: the Detritus Input and Removal Treatments experiment (Nadelhoffer et al. 2004), the CIFOR network (Nambiar et al. 2004), the Long-Term Soil Productivity network in North America (Powers et al. 2005), or the long-term monitoring networks in Fennoscandia (Smolander et al. 2010). To anticipate the evolution of ecosystem impacts, certain forest management practices (FMP) are often added to understand their effects on forest ecosystem functioning and to test the interaction between FMP and global changes. Furthermore, identifying the responses at an ecosystem scale requires sufficient surface areas and, consequently, an adapted size of the experimental sites (Fayle et al. 2015). Especially in the case of soil science studies in forestry domains, the experimental sites are mostly designed at a stand scale or higher (e.g., a watershed of several squared km).

For example, in the current forest LTERs, the study areas are approximately 3.5 to 4 ha per site for detecting responses at the ecosystem scale (Nambiar et al. 2004; Hope 2006; Smolander et al. 2010; Helmisaari et al. 2011). In such areas, experimental plots have variations in soil properties (chemical, biological, and physical) and local topography, which have an impact on the vegetation characteristics and dynamics. In forest soils, for example, there is a high horizontal spatial variability of chemical and physical soil parameters, even at small scales (Zhou et al. 2010). From the perspective of a long-term monitoring of FMP impacts on ecosystem functioning, it is essential to have ways of characterizing and taking into account the pre-existing ecosystem variability, in terms of the soil properties and the vegetation cover heterogeneity. Variability at the site scale must be taken into account before implementing the FMP to ensure that there is no interaction between the FMP and the main ecosystem properties in the establishment of the network. An efficient approach frequently used to determine the soil variability in agronomy consists of crossing geostatistical data (DEM, etc.) with the results of principal components analyses from a chemical description on the sampling grid (Nykänen et al. 2008; Sanchez et al. 2014). However, due to the costs of soil analyses, the authors have to focus on very few variables, such as soil moisture, phosphorus, nitrogen, carbon, or pollutant contents (Marchant et al. 2009; Lei et al. 2012).

Considering the increasing amount of interdisciplinary research and the number of parameters used to monitor in current LTER, along with the high cost of physical and chemical soil analyses, it seems necessary to develop an efficient tool that will integrate all these variables. Infrared spectroscopic approaches could be used to record all the necessary information and to provide an overview of local heterogeneity. Indeed, infrared reflectance spectrometry is a non-destructive physical analysis (Cécillon et al. 2009; Stenberg et al. 2010; BellonMaurel and McBratney 2011) that is frequently used to determine the chemical and physical properties of soil, in particular, the soil organic matter properties (Barthès et al. 2008; Ludwig et al. 2008). This method is used to accurately predict carbon and nitrogen concentrations (He et al. 2005; Brunet et al. 2007; Cécillon and Brun 2007), soil texture, or cation exchange capacity. Near-infrared spectrometry (NIRS) is used to predict carbon or nitrogen stocks, whereas mid-infrared spectrometry (MIRS) is a suitable method for evaluating organic matter composition (Ludwig et al. 2008; Tatzber et al. 2011). In arable soils, infrared spectroscopy was also used to predict the markers of soil biological activities, including enzyme activities, such as cellulase and phenoloxidase (Albrecht et al. 2008), the respiration rate, microbial biomass C, and the ergosterol content (Soriano-Disla et al. 2014; Ludwig et al. 2015). Soil nematode communities (Barthès et al. 2011) and earthworm activities can be predicted with a fingerprinting approach using near-infrared spectroscopy.

Consequently, infrared technologies are frequently used to characterize and map soil properties (Cécillon et al. 2009) related to agronomic or pollution issues at the stand to regional scale (for example, AMSR2 satellite imagery in Temimi et al. (2010)). The relationship between infrared spectra and the property of interest is calibrated using multivariate statistical approaches on a subsample, and the model is applied to the whole area from the infrared spectra measured on all samples to predict and monitor several soil variables, such as soil organic carbon (Vohland et al. 2011), soil nutrients (Gholizadeh et al. 2013), metal contaminants (Chodak et al. 2007; Horta et al. 2015), or indices of productivity in eucalyptus forests (Bikindou et al. 2012). To our knowledge, most of these studies integrated a calibration step between the spectra and chemical data (Lamsal 2009; Viscarra Rossel et al. 2010; Muñoz and Kravchenko 2011).

The basic idea of this study is that the variability of the spectra reflects the overall heterogeneity of the biological, chemical, and physical properties of the soil and thus can be used as such without preliminary calibration with the variables of interest. In a preceding study, Odlare et al. (2005) found that 
NIR spectral analysis provides a better description of soil spatial variations than the soil reference variables at the field scale, i.e., in a 3.2-ha experiment plot using the results from principal component analyses realized on the spectral data. Here, we propose to extend this result, and our hypothesis is that raw NIR and MIR spectra can be used as an integrated proxy of many soil properties. This method, in combination with dendrometric data, would be a rapid and a cost-effective way to optimize the design of experimental forest sites. We tested this hypothesis on forest LTERs, which exhibit substantial spatial heterogeneity (Smithwick et al. 2005).

\section{Materials and methods}

\subsection{Experimental sites}

This study was carried out at 11 experimental sites that belong to the MOS (Matières Organiques des Sols) network (Akroume 2014). Five beech stands (Fagus sylvatica L.) and six oak stands (Quercus petraea Matt. Liebl.) were selected in lowland production forests located in the northern half of France. The stands were selected to cover an age just before their current annual maximum increment (CAI), i.e., at an age between 30 and 60 years old (Table 1), and to avoid local constraints such as severe slopes or occurrence of hydromorphic soils. When available, the soil types and textures have been described from two pits (1 $\mathrm{m}$ deep) using the World Reference Base for Soil (WRB 2014).

This network is intended for long-term monitoring of the effects of intense biomass exportations on soil fertility, tree growth and health, and soil biodiversity (macro-, meso-, and microfauna). It requires experimental sites that have a study area that is sufficient to determine ecosystem responses.

The total area of a single experimental site is approximately 2-3 ha. We defined 12 subplots of $40 \mathrm{~m} \times 40 \mathrm{~m}$ within each site. Four treatments corresponding to four levels of biomass exportations will be studied at each experimental site. The planned treatments, as described in Akroume (2014), are as follows: (1) a control (stem only harvesting), (2) logging with residue removal, (3) logging with residue and forest floor removal, and (4) logging with residue removal and wood ash fertilization. They will be repeated three times per experimental site and their layout on each site was randomly drawn.

\subsection{Soil sampling and dendrometric measures}

At each site, we sampled the leaf litter and soil in a $50 \times 50 \mathrm{~cm}^{2}$ every $20 \mathrm{~m}$ before the onset of the in situ experiments. After the forest floor was collected, the mineral soil was sampled at three depths: 0-5, 5-10, and 10-20 cm. In each soil layer, three cores were collected and pooled to obtain a single composite sample per soil layer and point. According to the site configuration, this 20 -m sampling grid provided approximately 70 points per site, with a total of 280 samples per site for the four layers (leaf litter and the three soil depths). The sample point locations were recorded in the field using a Trimble Geo 5T (Trimble Navigation Ltd., Sunnyvale, CA, USA) terminal (accuracy of $0.5-1 \mathrm{~m}$ in forests) and plotted using the free GIS software Qgis 1.8 .0 (http://www.qgis.org/fr/site/). We measured the circumference at breast height and the dominant height $\left(H_{0}\right.$, height of the three largest trees) every $40 \mathrm{~m}$ to describe the forest stands. The trees were measured inside a 6-m-diameter circle, except for the trees with a circumference above $20 \mathrm{~cm}$, which were measured inside a $10-\mathrm{m}$ diameter circle. These measurements provided tree density (number of stems per ha), index of fertility (dominant height), the basal area ( $\mathrm{m}^{2}$ per ha), and the species composition.

\subsection{Mid-near-infrared spectroscopic analysis}

The soil and forest floor litter samples were sieved through a 4-mm mesh and dried at $30^{\circ} \mathrm{C}$ for 5 days before grinding. These ground samples were dried again at $30{ }^{\circ} \mathrm{C}$ for $24 \mathrm{~h}$ before infrared analysis. They were subjected to infrared (9997 to $2200 \mathrm{~cm}^{-1}$ ) and mid-infrared (5000 to $550 \mathrm{~cm}^{-1}$ ) scanning using a HTS-XT Bruker spectrometer (Vertex 70, NIR-MIR-MCT, Bruker Corporation, Billerica, MA, USA); the two sensors overlapped in the $2200-$ to $5000-\mathrm{cm}^{-1}$ region. We used the full range provided by each sensor, and the infrared scanner recorded the absorbance spectra for each sample.

\subsection{Chemical analyses}

We pooled the soil and litter samples per layer to obtain a single bulk sample for each $40 \mathrm{~m} \times 40 \mathrm{~m}$ plot delimited in the field. This resulted in 12 bulked samples for each site ( 3 repetitions by treatment) and a total of 512 bulked samples that corresponded to the 11 experimental sites $\times 4$ treatments $\times 3$ repetitions per treatment (except for the oak Compiègne site with only 2 repetitions) $\times 4$ studied layers (litter +3 soil depths). The carbon and nitrogen concentrations of the 512 bulked samples were measured using a Thermoquest elemental analyzer (NCS2500, EA/NA 1110).

A second level of pooling was performed on the soil layers. The three repetitions per treatment were combined, resulting in 132 samples, where the depths represented the repetitions for each treatment (11 experimental sites $\times 4$ treatments $\times 3$ soil layers). Figure 1 summarizes the different steps of sample pooling.

Complementary analyses to $\mathrm{C}$ and $\mathrm{N}$ were conducted on these 132 samples. The pooling permitted a reduction in the number of samples and resulted in homogenized combined samples by block. The chemical analyses were carried out at the INRA laboratory of Arras. Phosphorus was measured using the Duchaufour and Bonneau method (1959), and 


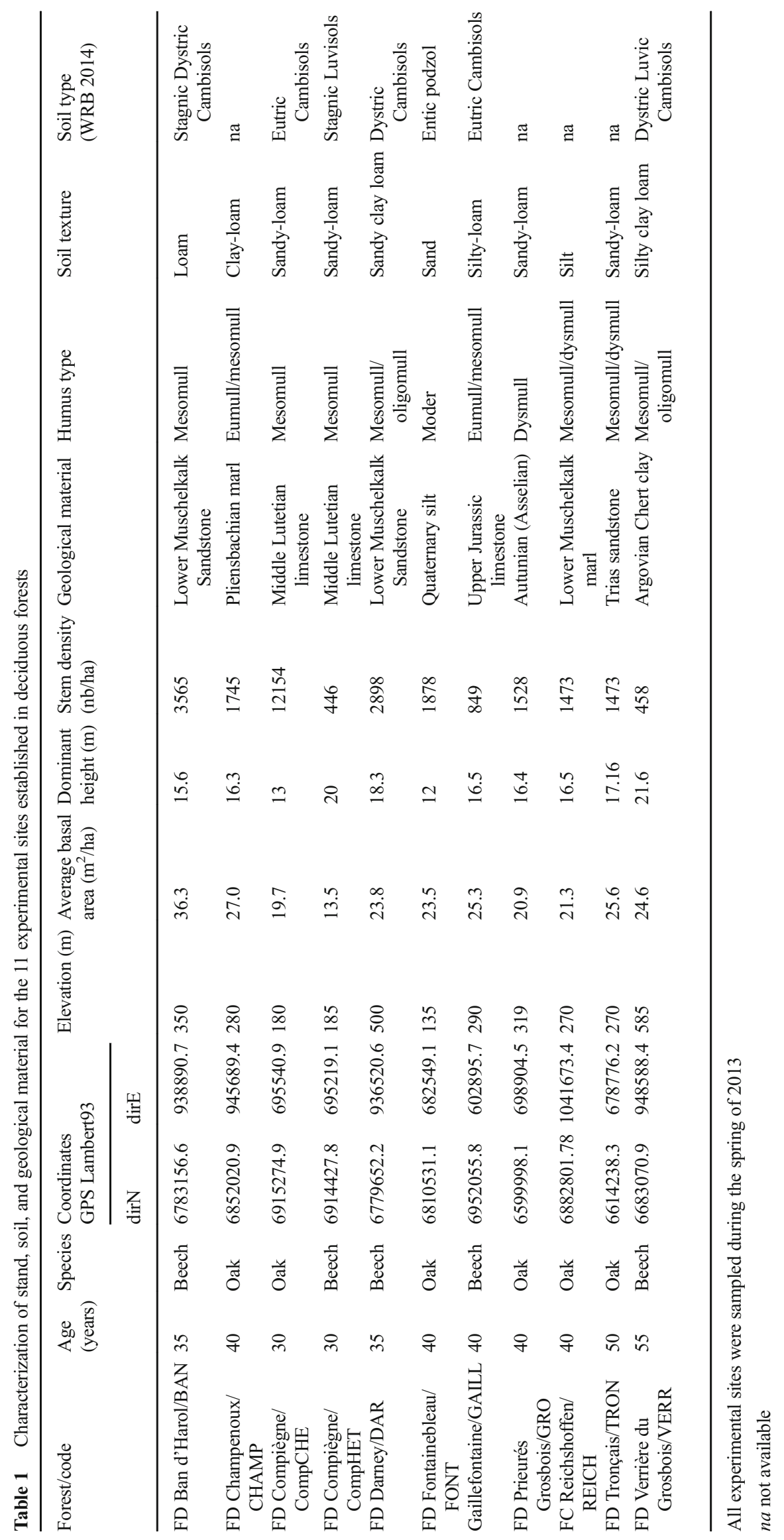




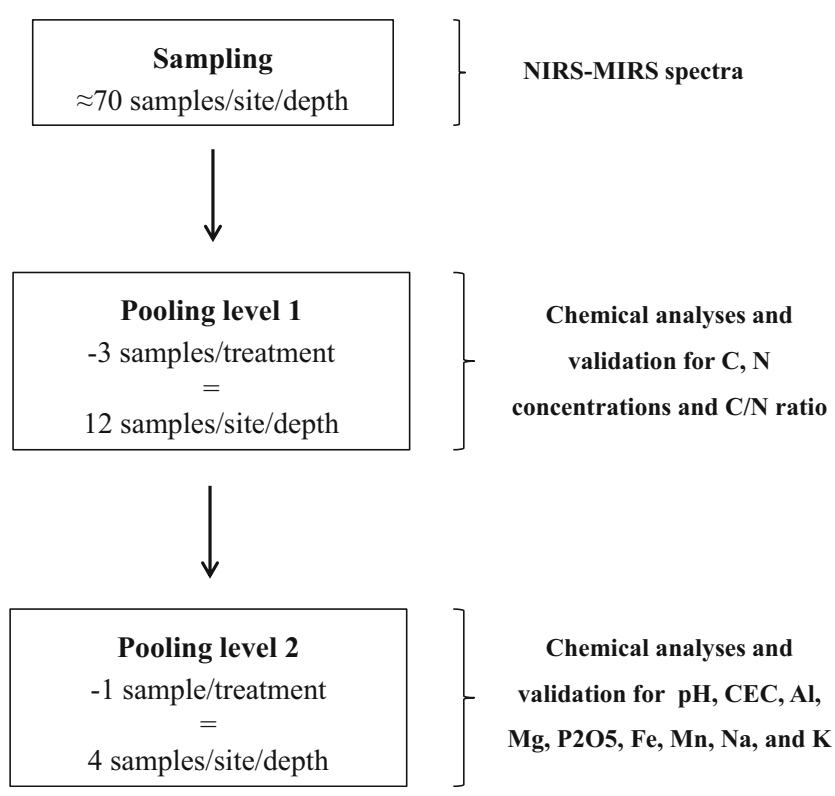

Fig. 1 Schematic plan of the different pooling steps for the spectral and the chemical characterization of soils. Around 70 samples per depth were collected on each site and used for the infrared spectroscopy analyses. A first pooling level provided 12 samples/site/depth which have been used to $\mathrm{C}$ and $\mathrm{N}$ analyses. The second pooling level provided four samples/site/ depth used for measuring the other soil properties $(\mathrm{pH}, \mathrm{CEC}, \mathrm{Al}, \mathrm{Mg}$, $\mathrm{P}_{2} \mathrm{O}_{5}, \mathrm{Fe}, \mathrm{Mn}, \mathrm{Na}$, and $\mathrm{K}$ ) analyses

exchangeable elements $(\mathrm{Ca}, \mathrm{K}, \mathrm{Mg}, \mathrm{Na}, \mathrm{Mn}, \mathrm{Al}, \mathrm{Fe})$ were extracted using cobaltihexammine chloride (Orsini and Rémy 1976). Furthermore, the $\mathrm{pH}\left(\mathrm{H}_{2} \mathrm{O}\right.$ and $\left.\mathrm{KCl}\right)$ was measured, and the $\mathrm{CEC}$ was estimated at soil $\mathrm{pH}$ after extraction with cobaltihexammine chloride. The soil chemical characteristics are given in table S1.

\subsection{Statistical analyses of NIRS-MIRS data}

For each of the 11 sites, the spectral data were saved as a matrix. Data analyses were conducted on the first derivate after standard normal transformation to accentuate spectral patterns (Reeves et al. 2002). Statistical analyses were carried out using SAS 9.2 software (SAS Inc., Cary, NC, USA).

The spectral data were then subjected to a principal components analysis (PCA) to determine the intra-site variability of the soils. For each of the 11 sites, the data set was composed of approximately 70 individuals (soil samples) and between 2566 (MIR) and 4044 (IR) variables. In all cases, the two first axes of the PCA were sufficient to explain more than $90 \%$ of the variance. Then, the PCA coordinates of the main components and the dendrometric characteristics for each subplot were synthesized to a single data set.

\subsection{Random drawing of the treatments' layout}

The procedure comprises two steps: (1) for each site, the treatments were assigned randomly to the subplots; (2) then interactions between the treatments' layout and variables mentioned in Section 2.5 were tested using ANOVA (proc GLM), with a significance threshold of $5 \%$. The two steps of the procedure were repeated until the analysis of variance did not reveal any significant effect between the treatments and the measured infrared (whatever the depth) or dendrometric data. The interactions between the treatments and spectral data were checked for all layers (soil and litter).

\subsection{Validation of the method}

Once the treatments have been assigned to each plot after the random drawing (as described in Section 2.6), it was necessary to cross-check with the chemical characteristics of the soil samples described in Section 2.4: if there was no interaction between the treatments' layout and the measured chemical properties, then the method is validated (i.e., the use of dendrometric variables and row NIRS spectra as synthetic surrogate of soil chemical properties allows to design efficiently experimental layout in forest ecosystems at low costs). This validation was performed on the first level of pooling (set of 512 samples) for the carbon and nitrogen concentrations and on the second level of pooling for the other chemical variables (set of 132 samples) (Fig. 1). For the first pooling, the interactions between the treatments and chemical properties were identified using nested proc GLM with a significance threshold of $5 \%$. The nested proc GLM permitted consideration of each soil depth separately.

In the second pooling data set, as the depths were used as replicates, the correlations existing between the different depths were taken into account in the "repeated measures anova" option in the SAS GLM procedure, taking sites as repetitions. To confirm the results, we also used mixed linear models with PROC MIXED in SAS. For each chemical element, the treatment effects were tested on each soil depth separately (fixed effects), and the 11 sites were taken as random effects parameters.

For both pooling datasets, our hypothesis was validated if no treatment effect was detected on the measured soil chemical properties and the dendrometric data when the treatment layouts were determined using only the infrared spectra and stand characteristics.

\section{Results}

\subsection{NIRS/MIRS spectra and principal component analyses}

For all sites, the two first components of the PCA explained more than $95 \%$ of the total variance of infrared spectral data. The coordinates of the first two components were mapped on the sampling grid, which revealed the occurrence of a local variability at the plot scale for the leaf litter and the three soil 
depths that were sampled. According to the experimental site, some spatial heterogeneity, soil homogeneity, or gradients of soil characteristics were highlighted (Fig. 2).

\subsection{Definitive treatments' layout}

The procedure described in Section 2.6 allowed to overcome the local heterogeneity of the soil and forest stands, or existing gradients revealed by infrared reflectance spectroscopy. The four treatments were settled on each experimental site accordingly to this result (Fig. 3). On average, four random drawings were necessary to obtain a suitable treatment arrangement (i.e., with no effect on dendrometric variables and spectra). When the ANOVA procedure detected treatment effects, they could have been due to soil variations, dendrometric characteristics, or a combination of both types of parameters.

\subsection{Validation of the repeated random drawing}

The nested analysis of variance exhibited no significant effect between the treatment layout and the carbon $(p=0.956)$ and
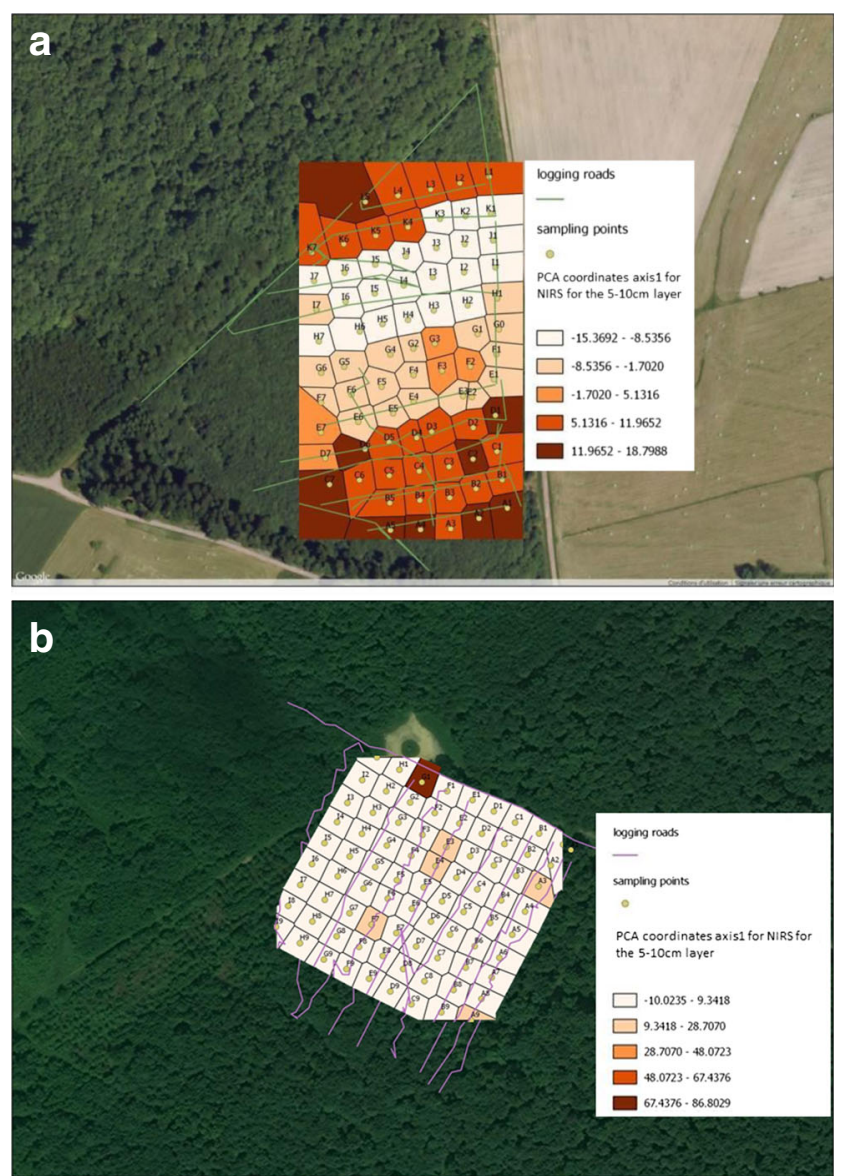

Fig. 2 Map of the axis 1 coordinates of the PCA for the infrared reflectance spectral data in the 5- to $10-\mathrm{cm}$ layer. The Darney experimental sites exhibits spatial gradient variability (a) whereas the Compiègne beech site reveals an overall homogeneity (b) nitrogen concentrations $(p=0.986)$. The ANOVA result was also non-significant for the $\mathrm{C} / \mathrm{N}$ ratio $(p=0.059)$. This result confirmed that there was no link between the local variations in the carbon and nitrogen concentrations or the $\mathrm{C} / \mathrm{N}$ ratios and the treatment design at the initial stage.

For all the other variables, the GLM procedure with "repeated measure anova" confirmed that the three soil depths were strongly correlated. The partial correlation coefficients were always highly significant and varied between 0.70 and $0.99\left(p<10^{-4}\right)$. Furthermore, there was no effect between the treatment layout and the different variables; for all elements, the GLM procedure exhibited no significant effect $(p>0.90)$.

The additional validation by a mixed linear model (PROC MIXED), considering the treatments and soil depths as fixed effects and the experimental sites as random effects, permitted us to test each soil layer independently. It confirmed this result and validated the absence of any initial interaction between the treatments and the soil chemical properties for each soil layer $(p>0.05)$.
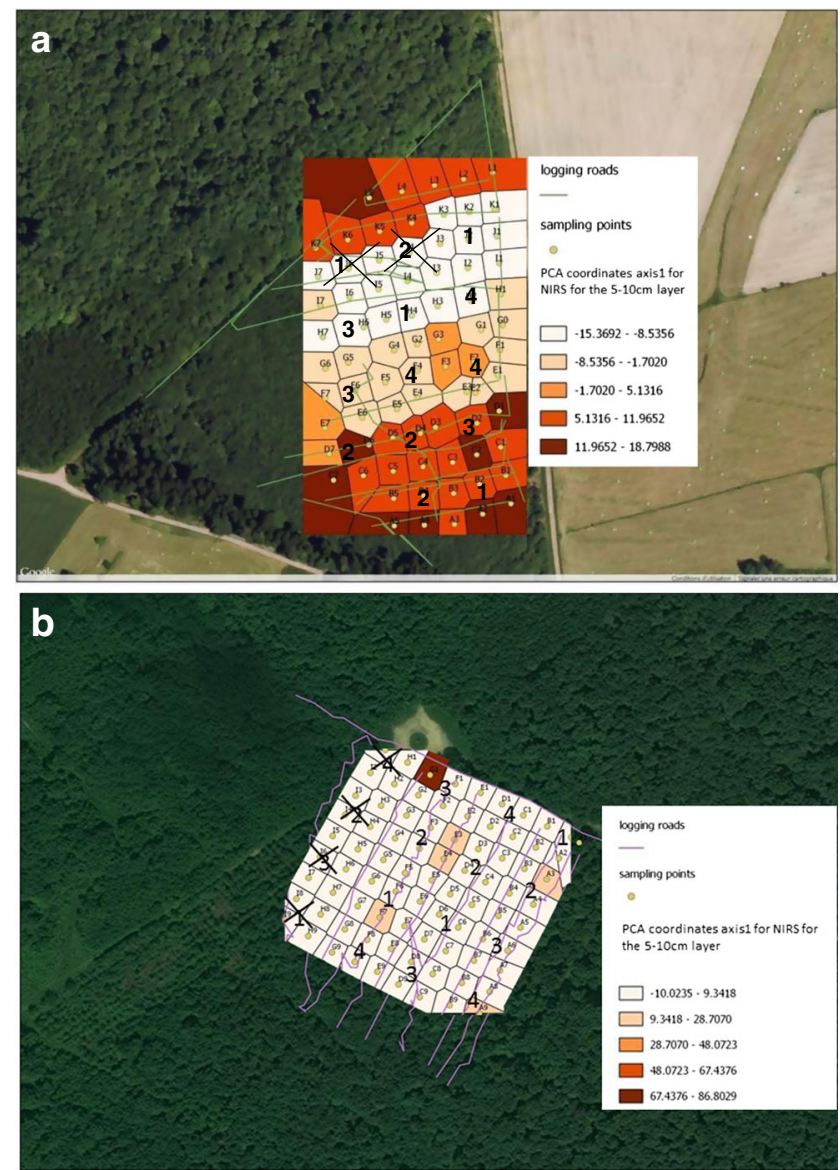

Fig. 3 Treatment layout at the Darney experimental site (a) and the Compiègne beech experimental site (b) overlapped with the map of the axis 1 coordinates of the PCA for the infrared reflectance spectral data. The crossed areas correspond to additional plots, which were not retained in the definitive experimental design

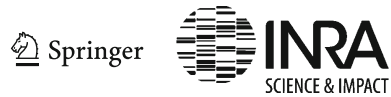




\section{Discussion}

This work aimed to develop a methodology for designing experimental sites in a long-term monitoring network where the soil organic matter is manipulated, such as in our context of increased forest harvesting. Then, for both the soil chemical measurements and the NIRS/MIRS spectral analyses, we focused on the topsoil (litter and the first $20 \mathrm{~cm}$ ), which is supposed to be more affected by organic matter removal than the deeper layers (Sayer 2005; Thiffault et al. 2011). Indeed, some studies in Eucalyptus plantations have not shown any effect of litter removal after 2 years on the carbon and nitrogen concentrations in mineral soil located at a depth below $15 \mathrm{~cm}$ (Versini et al. 2014). Furthermore, nitrogen from leaf litter degradation is mainly incorporated between depths of 15 and $30 \mathrm{~cm}$ (D'Annunzio et al. 2008). In temperate broadleaf forests, similar monitoring shows that most of the nitrogen is incorporated in the top $5 \mathrm{~cm}$ of the soil after 2 years (Swanston and Myrold 1997; Zeller et al. 2001). This finding is why we deliberately chose not to consider the spatial variability in deeper soil layers, despite their relevance for tree growth. For all of the soil chemical properties studied here, the random drawing based on infrared data was validated because there was no significant effect of treatment on the soil characteristics. It is interesting to note that the random drawing was validated even for the $\mathrm{C} / \mathrm{N}$ ratio and for some elements, such as $\mathrm{Fe}, \mathrm{Mn}, \mathrm{Na}$, or $\mathrm{K}$, whose concentrations are difficult to predict accurately by near- or mid-infrared spectroscopy (Bikindou et al. 2012; Kuang et al. 2012; Soriano-Disla et al. 2014). These results confirm that near- and mid-near-infrared spectra can be used as such in the design of experimental sites as a proxy of a large set of chemical properties of forest soils. This result is clearly new and generalizes the preceding study proposed by Odlare et al. (2005). In this study, we chose to focus only on chemical properties, even if we acknowledge that a relevant part of soil heterogeneity is driven by physical parameters. Complementary studies would be required to validate this method with physical characteristics, such as soil texture or structure.

For some experimental sites, in particular those with strong local variability of soil and stand characteristics, the mapping of the PCA coordinates on the spectral results revealed that the heterogeneity did not follow the same pattern across the four sampled layers. That is why it is essential to check the treatment effects using ANOVA on several depths and not only the upper layers. This point is important, not only for soil chemical properties but also for the soil microbial analysis, because soil fungi are also differentially distributed in the vertical soil profile (Dickie et al. 2002; Coince et al. 2013). Both soil variability and dendrometric characteristics have to be considered before implementing the treatments in situ, particularly when dendrometric data are very homogenous. In these cases, infrared data are the only parameters that permit the detection of local soil variations, which could interact with the treatment layout. Finally, it is essential to notice that the infrared data were validated using chemical analysis but not using biological activity factors, whereas the local variability observed using infrared spectroscopy could also be linked to the heterogeneous distribution of soil organisms (Ludwig et al. 2015). Indeed, Terhoeven-Urselmans et al. (2008) reported a high correlation between NIRS/MIRS and microbial properties, as ergosterol and microbial carbon measurements. Moreover, Morris (1999) found that considerable spatial variability in fungal and bacterial biomass exists at the $1-$ to $10-\mathrm{cm}$ scale. This author suggested that this variability could be adequately managed by sampling in a pattern, which takes into account components of this important biological variation.

Both near- and mid-infrared were taken into account for the 11 experimental sites. Mid-infrared spectra cover a larger range of frequencies and are more efficient to reflect the chemical properties of soil organic matter (Ludwig et al. 2008). They are preferentially used to predict organic components and exchangeable elements in litter and soil (Patzold et al. 2008), especially soil carbon, nitrate, metals, and microelements (Kuang et al. 2012), whereas near-infrared analyses associated with MIR reveal the physical properties of soil (Soriano-Disla et al. 2014). Near-infrared spectra are a good predictor of clay content, exchangeable K (Viscarra Rossel et al. 2006), and moisture content (Kuang et al. 2012). Evidence suggests that MIR spectroscopy provides an integrative overview of soil properties and will reveal more accurate local variations of existing gradients. Nevertheless, near infrared is still useful for identifying some variations and for crossing them with mid-infrared data for confirmation. Using both NIRS and MIRS analyses produces the most complete characterization of soil properties. Finally, Viscarra Rossel et al. (2006) emphasized the superior efficiency of MIR spectroscopy in the laboratory, whereas NIRS provides better results for in situ analyses, partly because of the sample preparation required for mid-infrared spectroscopy (Kuang et al. 2012).

\section{Outlook and conclusions}

NIRS-MIRS prospection is an accurate method for reflecting the local variability of forest soil for the main chemical variables. It allows for horizontal spatial heterogeneity to be overcome and limits the number of chemical analyses in the initial characterization of experimental sites.

Finally, NIR-MIR spectroscopy appears to be an efficient tool to describe the spatial heterogeneity of forest soil at the scale of a forest stand. Crossed with vegetation characteristics, it permits both belowground and dendrometric variability to be taken into account in the implementation of optimal experimental designs. It provides a reliable method that is 
applicable for the optimization of LTER plots in different types of ecosystems.

Acknowledgments We would like to thank the Office National des Forêts and the private owners for their collaboration and their permission for the achievement of the MOS network project. We also thank the Office National des Forêts and the Protection Judiciaire de la Jeunesse for the technical support, as well as all the students and colleagues who participated to the sampling campaigns. Language was revised by American Journal Experts association.

Compliance with ethical standards

Fundings French Agency for Environment and Energy Management (ADEME) through the RESPIRE project, by ANAEE-S and the European Regional Development Fund (FEDER) for the platform MPOETE used in this study. This work was supported by a grant overseen by the French National Research Agency (ANR) as part of the "Investissements d'Avenir" program (ANR-11-LABX-0002-01, Lab of Excellence ARBRE and ANR-11-INBS-0001, infrastructure ANAEE-S). EA's $\mathrm{PhD}$ is funded by Ministère de l'Agriculture, de l'Agroalimentaire et de la Forêt.

\section{References}

Akroume E (2014) Impacts d'un retrait intense des rémanents sur la fertilité des sols forestiers et sur leur biodiversité. Rev For Fr LXVI 4:573-578

Albrecht R, Joffre R, Petit JL, Terrom G, Périssol C (2008) Calibration of chemical and biological changes in cocomposting of biowastes using near-infrared spectroscopy. Environ Sci Technol 43:804-811

Barthès BG, Brunet D, Hien E, Enjalric F, Conche S, Freschet G, D'Annunzio R, Toucet-Louri J (2008) Determining the distributions of soil carbon and nitrogen in particle size fractions using near infrared reflectance spectrum of bulk soil samples. Soil Biol Biochem 40:1533-1537

Barthès BG, Brunet D, Rabary B, Ba O, Villenave C (2011) Near infrared reflectance spectroscopy (NIRS) could be used for characterization of soil nematode community. Soil Biol Biochem 43:1649-1659. doi:10.1016/j.soilbio.2011.03.023

Bellon-Maurel V, McBratney A (2011) Near-infrared (NIR) and midinfrared (MIR) spectroscopic techniques for assessing the amount of carbon stock in soils - critical review and research perspectives. Soil Biol Biochem 43:1398-1410. doi:10.1016/j.soilbio.2011.02.019

Bikindou FDA, Gomat HY, Deleporte P, Bouillet JP, Moukini R, Mbedi Y, Ngouaka E, Brunet D, Sita S, Diazenza JB, Vouidibio J, Mareschal L, Ranger J, Saint-André L (2012) Are NIR spectra useful for predicting site indices in sandy soils under Eucalyptus stands in Republic of Congo? For Ecol Manag 266:126-137. doi:10.1016 /j.foreco.2011.11.012

Brunet D, Barthès BG, Chotte JL, Feller C (2007) Determination of carbon and nitrogen contents in Alfisols, Oxisols and Ultisols from Africa and Brazil using NIRS analysis: effects of sample grinding and set heterogeneity. Geoderma 139:106-117. doi:10.1016/j. geoderma.2007.01.007

Cécillon L, Brun JJ (2007) Near-infrared reflectance spectroscopy (NIRS): a practical tool for the assessment of soil carbon and nitrogen budget. COST Action 639: Greenhouse-gas Budget of Soils Under Changing Climate and Land Use (BurnOut). 103-110

Cécillon L, Barthès BG, Gomez C, Ertlen D, Genot V, Hedde M, Stevens A, Brun JJ (2009) Assessment and monitoring of soil quality using near-infrared reflectance spectroscopy (NIRS). Eur J Soil Sci 60: 770-784. doi:10.1111/j.1365-2389.2009.01178.x

Chodak M, Niklińska M, Beese F (2007) Near-infrared spectroscopy for analysis of chemical and microbiological properties of forest soil organic horizons in a heavy-metal-polluted area. Biol Fertil Soils 44:171-180. doi:10.1007/s00374-007-0192-z

Coince A, Caël O, Bach C, Lengellé J, Cruaud C, Gavory F, Morin E, Murat C, Marçais B, Buée M (2013) Below-ground fine-scale distribution and soil versus fine root detection of fungal and soil oomycete communities in a French beech forest. Fungal Ecol 6: 223-235. doi:10.1016/j.funeco.2013.01.002

D’Annunzio R, Zeller B, Nicolas M, Dhôte JF, Saint-André L (2008) Decomposition of European beech (Fagus sylvatica) litter: combining quality theory and $15 \mathrm{~N}$ labelling experiments. Soil Biol Biochem 40:322-333. doi:10.1016/j.soilbio.2007.08.011

Dickie IA, Xu B, Koide RT (2002) Vertical niche differentiation of ectomycorrhizal hyphae in soil as shown by T-RFLP analysis. New Phytol 156:527-535

Duchaufour P, Bonneau M (1959) Une nouvelle méthode de dosage du phosphore assimilable dans les sols forestiers. Bull AFES 4:193198

Fayle TM, Turner EC, Basset Y, Ewers RM, Reynolds G, Novotny V (2015) Whole-ecosystem experimental manipulations of tropical forests. Trends Ecol Evol 30:334-346. doi:10.1016/j.tree.2015.03.010

Gholizadeh A, Borůvka L, Saberioon M, Vašát R (2013) Visible, nearinfrared, and mid-infrared spectroscopy applications for soil assessment with emphasis on soil organic matter content and quality: stateof-the-art and key issues. Appl Spectr 67:1349-1362. doi:10.1366 /13-07288

He Y, Song HY, Pereira AG, Gómez AH (2005) Measurement and analysis of soil nitrogen and organic matter content using near-infrared spectroscopy techniques. J Zhejiang Univ (Sci) 6B:1081-1086

Helmisaari HS, Hanssen KH, Jacobson S, Kukkola M, Luiro J, Saarsalmi A, Tamminen P, Tveite B (2011) Logging residue removal after thinning in Nordic boreal forests: long-term impact on tree growth. For Ecol Manag 261:1919-1927. doi:10.1016/j.foreco.2011.02.015

Hope GD (2006) Establishment of long-term soil productivity studies on acidic soils in the interior douglas-fir zone. LTSP Research Note. British Columbia Ministry of Forests and Range, Victoria BC, Canada, $\mathrm{p} 4$

Horta A, Malone B, Stockmann U, Minasny B, Bishop TFA, McBratney AB, Pallasser R, Pozza L (2015) Potential of integrated field spectroscopy and spatial analysis for enhanced assessment of soil contamination: a prospective review. Geoderma 241-242:180-209. doi:10.1016/j.geoderma.2014.11.024

Kuang B, Mahmood HS, Quraishi M, Hoogmoed WB, Mouazen AM, van Henten EJ (2012) Chapter four - sensing soil properties in the laboratory, in situ, and on-line: a review. In: Donald L. Sparks (ed) Adv. Agron. Academic Press, p 155-223

Lamsal S (2009) Visible near-infrared reflectance spectrocopy for geospatial mapping of soil organic matter. Soil Sci 174(1):35-44

Lei X, Li F, Zhou S, Li Y, Chen D, Liu H, Pan Y, Shen X (2012) Spatial variability and lateral location of soil moisture monitoring points on cotton mulched drip irrigation field. In: Li D, Chen Y (eds). Computer and computing technologies in agriculture V, IFIP advances in information and communication technology. Springer Berlin Heidelberg, pp. 247-257.

Ludwig B, Nitschke R, Terhoeven-Urselmans T, Michel K, Flessa H (2008) Use of mid-infrared spectroscopy in the diffuse-reflectance mode for the prediction of the composition of organic matter in soil and litter. J Plant Nutr Soil Sci 171:384-391. doi:10.1002 /jpln.200700022

Ludwig B, Sawallisch A, Heinze S, Joergensen RG, Vohland M (2015) Usefulness of middle infrared spectroscopy for an estimation of chemical and biological soil properties - underlying principles and 
comparison of different software packages. Soil Biol Biochem 86: $116-125$

Marchant BP, Newman S, Corstanje R, Reddy KR, Osborne TZ, Lark RM (2009) Spatial monitoring of a non-stationary soil property: phosphorus in a Florida water conservation area. Eur J Soil Sci 60:757-769. doi:10.1111/j.1365-2389.2009.01158.x

Morris SJ (1999) Spatial distribution of fungal and bacterial biomass in southern Ohio hardwood forest soils: fine scale variability and microscale patterns. Soil Biol Biochem 31:1375-1386

Muñoz JD, Kravchenko A (2011) Soil carbon mapping using on-the-go near infrared spectroscopy, topography and aerial photographs. Geoderma 166:102-110. doi:10.1016/j.geoderma.2011.07.017

Nadelhoffer KJ, Boone RD, Bowden RD, Canary JD, Kaye J, Micks P et al (2004) The DIRT experiment: litter and root influences on forest soil organic matter stocks and function. In: Foster D, Aber J (eds) Forests in time: the environmental consequences of 1000 years of change in New England. Yale Univ. Press, New Haven, pp 300-315

Nambiar EK, Ranger J, Tiarks A, Toma T (eds) (2004) Site management and productivity in tropical plantation forests: proceedings of workshops in Congo July 2001 and China February 2003. Center for International Forestry Research, Bogor

Nykänen A, Jauhiainen L, Kemppainen J, Lindström K (2008) Field-scale spatial variation in yields and nitrogen fixation of clover-grass leys and in soil nutrients. Agr Food Sci 17:376-393. doi:10.2137 $/ 145960608787235568$

Odlare M, Svensson K, Pell M (2005) Near infrared reflectance spectroscopy for assessment of spatial soil variation in an agricultural field. Geoderma 126:193-202. doi:10.1016/j.geoderma.2004.09.013

Orsini L, Rémy JC (1976) Utilisation du chlorure de Cobaltihexammine pour la détermination simultanée de la capacité d'échange et des bases échangeables des sols. Sci Sol 4:269-275

Patzold S, Mertens FM, Bornemann L, Koleczek B, Franke J, Feilhauer H, Welp G (2008) Soil heterogeneity at the field scale: a challenge for precision crop protection. Precis Agric 9:367-390. doi:10.1007 /s11119-008-9077-x

Powers R, Scott D, Sanchez F, Voldseth R, Page-Dumroese D, Elioff J, Stone D (2005) The North American long-term soil productivity experiment: findings from the first decade of research. For Ecol Manag 220:31-50. doi:10.1016/j.foreco.2005.08.003

Reeves J, McCarty G, Mimmo T (2002) The potential of diffuse reflectance spectroscopy for the determination of carbon inventories in soils. Environ Pollut 116:S277-S284

Sanchez MGB, Marques J, Siqueira DS, Camargo LA, Pereira GT (2014) Delineation of specific management areas for coffee cultivation based on the soil-relief relationship and numerical classification. Precis Agric 14:201-214. doi:10.1007/s11119-012-9288-Z

Sayer EJ (2005) Using experimental manipulation to assess the roles of leaf litter in the functioning of forest ecosystems. Biol Rev 81(1):131. doi: $10.1017 / \mathrm{S} 1464793105006846$

Smithwick EA, Mack MC, Turner MG, Chapin FS III, Zhu J, Balser TC (2005) Spatial heterogeneity and soil nitrogen dynamics in a burned black spruce forest stand: distinct controls at different scales. Biogeochemistry 76:517-537

Smolander A, Kitunen V, Tamminen P, Kukkola M (2010) Removal of logging residue in Norway spruce thinning stands: long-term changes in organic layer properties. Soil Biol Biochem 42:12221228. doi:10.1016/j.soilbio.2010.04.015

Soriano-Disla JM, Janik LJ, Viscarra Rossel RA, Macdonald LM, McLaughlin MJ (2014) The performance of visible, near-, and mid-infrared reflectance spectroscopy for prediction of soil physical, chemical, and biological properties. Appl Spectrosc Rev 49:139 186. doi:10.1080/05704928.2013.811081

Stenberg B, Viscarra Rossel RA, Mouazen AM, Wetterlind J (2010) Visible and near infrared spectroscopy in soil science. in: Adv. Agron. Elsevier, p 163-215

Swanston CW, Myrold DD (1997) Incorporation of nitrogen from decomposing red alder leaves into plants and soil of a recent clearcut in Oregon. Can J For Res 27:1496-1502

Tatzber M, Mutsch F, Mentler A, Leitgeb E, Englisch M, Zehetner F, Djukic I, Gerzabek MH (2011) Mid-infrared spectroscopy for topsoil layer identification according to litter type and decompositional stage demonstrated on a large sample set of Austrian forest soils. Geoderma 166:162-170. doi:10.1016/j. geoderma.2011.07.025

Temimi M, Leconte R, Chaouch N, Sukumal P, Khanbilvardi R, Brissette F (2010) A combination of remote sensing data and topographic attributes for the spatial and temporal monitoring of soil wetness. J Hydrol 388:28-40. doi:10.1016/j.jhydrol.2010.04.021

Terhoeven-Urselmans T, Schmidt H, Georg Joergensen R, Ludwig B (2008) Usefulness of near-infrared spectroscopy to determine biological and chemical soil properties: importance of sample pre-treatment. Soil Biol Biochem 40:1178-1188. doi:10.1016/j.soilbio.2007.12.011

Thiffault E, Hannam KD, Paré D, Titus BD, Hazlett PW, Maynard DG, Brais S (2011) Effects of forest biomass harvesting on soil productivity in boreal and temperate forests - a review. Environ Rev 19: 278-309. doi:10.1139/a11-009

Versini A, Mareschal L, Matsoumbou T, Zeller B, Ranger J, Laclau JP (2014) Effects of litter manipulation in a tropical Eucalyptus plantation on leaching of mineral nutrients, dissolved organic nitrogen and dissolved organic carbon. Geoderma 232-234:426-436. doi:10.1016/j.geoderma.2014.05.018

Viscarra Rossel RA, Walvoort DJJ, McBratney AB, Janik LJ, Skjemstad JO (2006) Visible, near infrared, mid infrared or combined diffuse reflectance spectroscopy for simultaneous assessment of various soil properties. Geoderma 131:59-75. doi:10.1016/j.geoderma.2005.03.007

Viscarra Rossel RA, Rizzo R, Demattê JAM, Behrens T (2010) Spatial modeling of a soil fertility index using visible-near-infrared spectra and terrain attributes. Soil Sci Soc Am J 74:1293. doi:10.2136 /sssaj2009.0130

Vohland M, Besold J, Hill J, Fründ HC (2011) Comparing different multivariate calibration methods for the determination of soil organic carbon pools with visible to near infrared spectroscopy. Geoderma 166:198-205. doi: 10.1016/j.geoderma.2011.08.001

Zeller B, Colin-Belgrand M, Dambrine E, Martin F (2001) Fate of nitrogen released from $15 \mathrm{~N}$-labeled litter in European beech forests. Tree Physiol 21:153-162

Zhou Y, Wand S, Lu H, Xie L, Xiao D (2010) Forest soil heterogeneity and soil sampling protocols on limestone outcrops: example from China. ACTA CARSOLOGICA 1:39 